DOI: 10.12957/demetra.2016.15944

\title{
"É assim, com vergonha de sair com ele": percepções de mães de crianças desnutridas, em um meio socialmente desfavorecido
}

\author{
"It's like this, i'm ashamed to go out with him": the perceptions of the mothers of \\ malnourished children, in a context of social disadvantage
}

Maria de Lourdes Benevides de Magalhães' Márcia Maria Tavares Machado' Álvaro Jorge Madeiro Leite' Alba Maria Pinho de Carvalho² Ângela Cardoso Andrade Timóteo da Silva ${ }^{3}$

1 Universidade Federal do Ceará, Faculdade de Medicina. Fortaleza-CE, Brasil.

${ }^{2}$ Universidade Federal do Ceará, Departamento de Ciências Sociais. Fortaleza-CE, Brasil.

${ }^{3}$ Universidade de Fortaleza, Centro de Ciências da Saúde. Fortaleza-CE, Brasil.

Correspondência / Correspondence Maria de Lourdes Benevides de Magalhães E-mail: lurdesmag5@yahoo.com.br

\section{Resumo}

Objetivo: Compreender as percepções de mães de crianças desnutridas sobre sua realidade de vida, considerando seu contexto de vulnerabilidade social e pobreza. Metodologia: A pesquisa foi feita com sete mães de crianças desnutridas do Instituto de Promoção da Nutrição e do Desenvolvimento Humano (IPREDE), situado em Fortaleza, Ceará, de maio a outubro de 2011. Adotou-se a metodologia qualitativa, desenvolvendo percursos etnográficos com observações sistemáticas e entrevistas semiestruturadas. O material empírico foi estudado conforme a técnica de análise de discurso. Resultados: Revelam forte associação entre desnutrição infantil e dificuldades na maternidade e no vínculo mãe e filho. As mulheres relataram dificuldades em exercer a maternidade por se sentirem despreparadas e desprotegidas; foram vítimas de violência e abandono no período da infância e/ou durante a gravidez de seus filhos; mencionaram recusa alimentar dos filhos aos alimentos preparados por elas, evidenciando uma ruptura no vínculo com a mãe. Considerações Finais: Supõe-se que programas de intervenção nutricional poderão obter resultados mais satisfatórios quando valorizada a história de vida das mães como fator coadjuvante no processo de determinação e recuperação da desnutrição. Entende-se que uma atenção psicoemocional mais individualizada e aprofundada à díade poderá favorecer o fortalecimento do vínculo mãe e filho.

Palavras-chave: Transtornos da Nutrição Infantil. Comportamento Materno. Saúde da Criança. Desnutrição. Poder Familiar. 


\section{Abstract}

Objective: This study aims to understand the perceptions of the mothers of malnourished children regarding the realities of their lives, considering the context of their social vulnerability and poverty. Methodology: The research was conducted with seven women, mothers of malnourished children cared for at the Institute for the Promotion of Nutrition and Human Development - IPREDE, located in Fortaleza, Ceará, between the months of May and October 2011. A qualitative methodology was adopted developing ethnographic accounts with systematic observations and semi-structured interviews. The empirical material obtained was analyzed using discourse analysis techniques. Results: The results revealed a strong link between child malnutrition and difficulties with motherhood and mother/child bonding. The women reported difficulties in living and enjoying motherhood because they feel unprepared and unprotected; they were victims of violence and abandonment during infancy and/or during their pregnancies. They have also mentioned their children's refusal to eat the food which they have prepared, showing an evidence of a rupture in the bond with the mother. Conclusion: It is concluded that nutritional intervention programs may obtain more satisfactory results when the mother's life story is valued as a supporting factor in the process of determining and recovering from malnutrition. It is understood that a more individualized and deep psycho-emotional attention to the dyad may favor the strengthening of the bond between the mother and the child.

Key words: Child Nutrition Disorders. Maternal Behavior. Child Health. Malnutrition. Parenting.

\section{Introdução}

A Organização Mundial de Saúde (OMS) divulga que, em países em desenvolvimento, mais de $50 \%$ das mortes de crianças abaixo de cinco anos estão relacionadas à desnutrição, a maior parte desse percentual deve-se à grande suscetibilidade das crianças desnutridas a doenças infecciosas e parasitárias. ${ }^{1,2}$

No Brasil, o declínio da prevalência da desnutrição observado ao longo das décadas é expressivo, fundamentalmente na região Nordeste do país, onde a desnutrição foi reduzida em um terço de 1986 a 1996 (de 33,9\% para 22,2\%) e em quase três quartos de 1996 a 2006 (de 22,2\% para 5,9\%). Mantida esta taxa de declínio constatada entre 1996 e 2006, o problema da desnutrição infantil na 
região Nordeste, como também no restante do país, poderia ser considerado controlado em menos de dez anos. Para se chegar a este resultado, no entanto, será preciso manter o aumento do poder aquisitivo dos mais pobres e assegurar investimentos públicos para completar a universalização do acesso a serviços essenciais de educação, saúde e saneamento. ${ }^{1}$

A desnutrição infantil é considerada atualmente um problema multifatorial. ${ }^{3}$ Vale ressaltar aqui que este agravo não deve ser entendido apenas como uma doença orgânica, mas como fenômeno global, expressão de múltiplas dimensões, caracterizando uma série de situações e condições de vida desfavoráveis que atuam em um indivíduo e/ou coletividade. ${ }^{4,5}$ A rigor, no fenômeno da desnutrição infantil interferem condições objetivas de pobreza e vulnerabilidade social, como também dimensões subjetivas da trajetória de vida da própria mãe e das relações que configuram o contexto sociofamiliar.

Vários autores alertam para a interferência dos condicionantes emocionais, incluindo o vínculo mãe e filho, como importante determinante da desnutrição, sugerindo ainda que estados extremos de desnutrição podem estar associados a faltas e/ou falhas nutricionais, bem como a vivências de privação ou excesso psicoafetivo. Para a compreensão da situação nutricional da criança, a alimentação deve ser avaliada para além das necessidades fisiológicas, uma vez que os primeiros conflitos interacionais encontram expressão na esfera da alimentação. ${ }^{6,7}$

Como uma referência analítica é muito importante levar em conta no âmbito da investigação sobre a desnutrição infantil, como fenômeno sociocultural, as representações existentes no imaginário social sobre a criança desnutrida. Elas são múltiplas e revelam padrões e valores da cultura vigente interferindo nas percepções das mães de crianças desnutridas.

A desnutrição, várias vezes desvelada apenas em termos de falha de crescimento, não deixa de ser, nos dias de hoje, a principal causa de morte entre as crianças menores de cinco anos, no mundo. Para cada caso grave há muitos outros menos graves, às vezes sem sinais clínicos típicos da desnutrição. Diante do fato de que há menos crianças gravemente desnutridas, passou-se a minimizar a importância do problema e até a ignorar a existência da epidemia silenciosa de fome oculta e de desnutrição, expressa pelo contingente de crianças com desnutrição moderada e leve, por se apresentar de modo menos evidente..$^{8,9}$

Considerando que a desnutrição infantil ainda é um problema sério em nosso meio, apesar da grande redução no Ceará nos últimos anos, ${ }^{10}$ esta pesquisa ${ }^{a}$ teve como intenção dar visibilidade a essas famílias, colocando em foco a figura da mãe em sua dupla condição de mulher e cuidadora. O nosso propósito é compreender as percepções das mães de crianças desnutridas sobre o cuidado materno, em um meio socialmente desfavorecido. 


\section{Metodologia}

Diante do contexto mencionado, foi feita uma investigação qualitativa, que se afirma no campo da subjetividade e do simbolismo, buscando entender, descrever e explicar os fenômenos sociais. ${ }^{11}$ Estratégias metodológicas de enfoque qualitativo podem contribuir significativamente na compreensão da dimensão subjetiva inerente ao ato alimentar humano, proporcionando entendimento de intervenções, adequação de programas e desenvolvimento de políticas, haja vista que tais ações necessitam considerar o contexto social, econômico e cultural em que esses programas estão inseridos. ${ }^{12}$ Existe, nesta abordagem, o propósito de analisar o significado atribuído pelos sujeitos aos fatos, relações e práticas, avaliando tanto as interpretações quanto as ações dos atores sociais. ${ }^{13}$

Nos últimos decênios, surgiu um interesse crescente na pesquisa em Saúde Coletiva para se entender a construção cultural da saúde e da doença elaborada pelos diferentes grupos culturais e estudada por meio da abordagem etnográfica. Para Minayo, ${ }^{11}$ a etnografia (ou etnometodologia) refere-se a um conjunto de estratégias de pesquisa que buscam a descrição minuciosa dos objetos que investiga. Seus desenhos operacionais preconizam a observação direta e a investigação detalhada dos fatos no lugar em que ocorrem, com o fim de obter uma descrição minuciosa e densa das pessoas, de suas relações e de sua cultura.

Nesse sentido, empreendemos um esforço etnográfico por meio de observações sistemáticas e entrevistas semiestruturadas, buscando compreender as mães nas suas trajetórias e no seu universo de vida.

\section{Sujeitos da pesquisa e local do estudo}

As mulheres, sujeitos desta investigação, são participantes do Instituto de Promoção da Nutrição e do Desenvolvimento Humano (IPREDE), situado em Fortaleza, Ceará. Essa Instituição é referência no Estado do Ceará na área de nutrição infantil. Sua clientela é oriunda fundamentalmente do município de Fortaleza e, em menores proporções, de municípios vizinhos. É uma entidade sem fins lucrativos que vem ampliando seus trabalhos e implementando um conjunto de estratégias de ação direcionadas à promoção do desenvolvimento neuromotor, sensorial e psicoafetivo da criança, assim como de competências familiares, direcionadas especialmente às mães. ${ }^{14}$

As idades das sete mães investigadas variaram de 26 a 56 anos; quanto à escolaridade, duas nunca estudaram, as outras fizeram o primeiro grau incompleto; três delas trabalham e as outras quatro revelaram intenção de trabalhar, mas não têm com quem deixar os filhos. Apresentamos em um quadro explicativo (quadro 1) os dados socioeconômicos mencionados, com o intuito de facilitar a visualização do perfil geral de todas as mulheres envolvidas neste trabalho. 
Quadro 1. Perfil socioeconômico das mães acompanhadas na pesquisa. 2011.

\begin{tabular}{|c|c|c|c|c|c|c|c|c|c|c|}
\hline $\begin{array}{l}\text { Nome da } \\
\text { mãe }\end{array}$ & Idade & Escolaridade & Profissão & $\begin{array}{l}\text { Sofreu } \\
\text { maus- } \\
\text { tratos? }\end{array}$ & $\begin{array}{l}\text { № de } \\
\text { filhos }\end{array}$ & $\begin{array}{c}\text { Filho } \\
\text { desnutrido }\end{array}$ & $\begin{array}{c}\text { Tem } \\
\text { companheiro? }\end{array}$ & $\begin{array}{c}\text { É pai } \\
\text { do filho } \\
\text { desn.? }\end{array}$ & $\begin{array}{l}\text { Renda } \\
\mathrm{R} \$\end{array}$ & $\begin{array}{c}\text { Moram } \\
\text { na casa } \\
\text { (pessoas) }\end{array}$ \\
\hline Amália & 26 & 6a série & Do lar & Sim & 3 & Ian & Não & --- & 250,00 & 7 \\
\hline Cláudia & 41 & $1^{\underline{a}}$ série & Do lar & Sim & 6 & $\begin{array}{l}\text { Vera e } \\
\text { Vânia }\end{array}$ & Sim & Sim & 640,00 & 6 \\
\hline Débora & 43 & $7 \underline{a}$ série & Vendas & Sim & 3 & Renato & Sim & Não & 600,00 & 5 \\
\hline Joelma & 56 & Analfabeta & Vendas & Sim & 6 & Wendel & Não & --- & 300,00 & 6 \\
\hline Gil & 29 & 7 a série & Do lar & Sim & 6 & Gabriel & Sim & Sim & 1000,00 & 8 \\
\hline Janaína & 38 & Analfabeta & Faxineira & Sim & 8 & Gláucia & Sim & Sim & 900,00 & 10 \\
\hline Marília & 29 & $1^{a}$ série & Do lar & Sim & 4 & $\begin{array}{l}\text { João e } \\
\text { Jéssica }\end{array}$ & Sim & Não & 360,00 & 4 \\
\hline
\end{tabular}

Fonte: Pesquisa Direta.

Dentre as 60 crianças desnutridas com magreza ou magreza extrema identificadas na relação da instituição, excluímos os casos de comprometimento do estado nutricional por problemas neurológicos ou sindrômicos, como também aquelas que moravam fora de Fortaleza por motivo de dificuldade de acesso às suas residências. Várias dessas crianças não estavam frequentando o IPREDE há mais de três meses, portanto seus prontuários foram arquivados.

\section{Coleta das informações e período do estudo}

A pesquisa foi concretizada entre os meses de maio e outubro de 2011. Foram realizados acompanhamentos da vida dessas mulheres no seu local de moradia, nas idas ao atendimento em Unidades de Saúde e no IPREDE.

Após aprovação pelo Comitê de Ética em Pesquisa da Universidade Federal do Ceará (parecer no 070/11) e anuência da instituição, observações sistemáticas e entrevistas semiestruturadas foram realizadas com sete mães de crianças desnutridas (com idades entre 3 e 8 anos), selecionadas a 
partir dos prontuários e de conversa com os profissionais, apresentando idade acima de 18 anos e que estavam sendo acompanhadas há mais de seis meses, tendo desenvolvido vínculo com a instituição e participado de vários projetos e de setores de acompanhamento à mãe e à criança. Das sete mulheres participantes, três frequentavam a instituição no turno da tarde e quatro, no turno da manhã.

Solicitamos às nossas depoentes uma visita mais aproximada, indo nas suas casas, onde pudemos observar como é o ambiente domiciliar e o lugar social onde vivem: como convivem no dia a dia com o filho desnutrido, em busca, por exemplo, do alimento e de melhores condições de vida; de que outras instituições participam, que apoio recebem; como é a vizinhança, qual o contexto socioeconômico e cultural da comunidade.

As entrevistas (a primeira realizada no IPREDE e a segunda, em seus lares) foram gravadas com o consentimento das depoentes, durando de 30 a 60 minutos de conversação. Elas assinaram o Termo de Consentimento Livre e Esclarecido após explicados os objetivos do estudo e a proteção do anonimato. Utilizou-se como questão norteadora: como é para a senhora ser mãe de uma criança com desnutrição?

\section{Organização e análise do material}

A análise foi realizada pela leitura exaustiva do material, para explorá-lo e formular o tratamento e a interpretação dos dados. Na ocasião, reconhecemos o contexto da produção do discurso para codificá-lo, identificando suas unidades de registro ou de significação. As unidades de significação foram agrupadas como dimensões que revelaram significados constituídos com arrimo na realidade vivida pelas mulheres. As dimensões, por sua vez, foram reunidas em categorias centrais.

Os nomes verdadeiros das mães e de seus filhos foram substituídos por nomes fictícios, preservando-se a letra inicial de cada nome.

\section{O Cuidado materno à criança desnutrida}

Cuidar de uma criança é tarefa complexa, principalmente em um contexto de perdas e iniquidades em que vive a maioria das mulheres que frequentam o IPREDE: falta de um companheiro presente e participativo na sua função paterna, de condições financeiras para sustentar o filho, de conhecimento sobre o desenvolvimento de uma criança, de referenciais de afeto seguros e estruturantes na infância da mãe para subsidiar o equilíbrio emocional necessário à delicada função materna, além da inexistência de moradia, de creches, de assistência médica de qualidade, dentre tantas outras. 
Cuidar de um filho com desnutrição em meio a todas essas vulnerabilidades envolve aspectos psicossociais com origem em características comuns manifestadas pelas mulheres, como medo, tristeza, vergonha, apreensão, conflito, angústia, culpa, raiva, indignação, somatização, superação. No que concerne ao estudo dos hábitos ou práticas alimentares, é preciso compreender como os indivíduos interpretam o mundo e constroem significados, como se motivam e se relacionam, contextualizando a comida como mediadora de relações. ${ }^{12}$

Com base na exposição dos sentimentos e mais as percepções reveladas durante as entrevistas com relação à maternidade e ao cuidado por parte de mães das crianças desnutridas, surgiram as seguintes subcategorias: (a) "Eu não achei nada fácil ser mãe”; (b) Ser mãe: conflitos e contradições; (c) os sentimentos diante da desnutrição do filho.

Estas subcategorias, abordadas a seguir, ajudam a compreender o contexto de vida dessas mulheres.

\section{(a) "Eu não achei nada fácil ser mãe"}

As mulheres demonstram seus sentimentos e dificuldades em ser mães. Seus discursos parecem revelar o peso da função materna em um contexto de privações, somando-se à ausência de uma figura paterna estável e presente. A maioria delas deflagra suas sensações ante a responsabilidade em assumir os dois papéis, de mãe e de pai, pensando em alguns momentos em desistir dessa condição materna, sentindo-se estressadas, tristes ou "conformadas", como demonstram em suas falas:

Eu fico conformada porque assim nós que somo mãe, é pra passar tudo isso, eu não achei nada fácil ser mãe, é tanto que às vezes eu falo que não gostei de ser mãe, porque é difícil [voz mais aguda] ... Pra gente ser mãe, ser a mãe e o pai ao mesmo tempo, ter que assumir de tudo. Ai eles exigem coisas às vezes que a gente não pode. [...] Assim, se eu pensasse, se a gente visse esse ponto...se tivesse pensado mais não era? (DÉBORA)

[...] a coisa pior que existe no mundo, se eu soubesse que era tão ruim fazer papel de pai e de mãe, eu nunca tinha querido homem na minha vida, que é muito pesado pra uma pessoa. (JOELMA)

Mas meu coração fica tão pequeno, tão apertado, as vez me dá vontade de jogar tudo pro alto, dá vontade de mandar aqueles meninos tudo pra casa do pai deles, mas as vez eu penso antes de fazer. [...] eles me estressam demais. (MARÍLIA)

Não desejar ser mãe e vivenciar rejeição, frustrações e medos por essa condição existencial podem desencadear distúrbios alimentares infantis como consequência das dificuldades no vínculo mãe e filho, na visão de diversos autores. ${ }^{15-17}$

A nutrição fisiológica está relacionada à nutrição afetiva desde os primeiros contatos da díade. Não podemos deixar de frisar que a preparação para a maternidade se dá muito antes do nascimento de uma criança, estando vinculada às experiências das infâncias dos próprios pais. ${ }^{18,19}$ 
Ser mãe em um contexto simbólico e cultural é ter capacidade de "nutrir" um ser humano, em todas as dimensões de que ele necessita. A pequenês e magreza das crianças desnutridas, no caso de nosso estudo, parecem associadas à situação vivencial das mães, com todo o peso e as marcas de suas histórias. Não comer, ou desenvolver algum distúrbio alimentar, é assinalar que a mãe não tem o principal alimento a oferecer: o bem-estar em receber o filho, a alegria e o regozijo em seu desenvolvimento. Portanto, de maneira inconsciente, as mensagens subliminares dessas mães podem resultar em um questionamento no psiquismo de seus filhos: desenvolver para quê, se o solo seguro para esse desenvolvimento é escasso?

Para a teoria psicanalítica, alimentar/ser alimentado refere-se às primeiras trocas entre o bebê e seu cuidador, mudanças que implicam uma passagem do real, da necessidade fisiológica para o mundo simbólico, da demanda e do desejo, delimitando um tempo originário no advir do sujeito. O alimento ganha, nos primórdios da existência, um estatuto simbólico, podendo ser aceito ou recusado pela criança, dependendo do sentido que lhe é conferido na relação com a mãe. Sendo assim, a criança pode apresentar uma recusa persistente do alimento como uma resposta ao que se passa entre ela e seus cuidadores. ${ }^{20}$

No perfil das mulheres, pudemos perceber que todas elas sofreram maus-tratos, não receberam apoio de familiares ou do pai da criança, passando por momentos de violência e abandono durante a gravidez e não desejando aquele filho que iria nascer em um contexto de grande tensão e insegurança. Tais achados são semelhantes aos descritos por outros autores ${ }^{7}$ sobre a relação entre gravidez indesejada e fatores importantes para a formação e o desenvolvimento do vínculo mãefilho, postulando que a desnutrição está associada a uma falta de sincronia entre a mãe e o bebê, além da falta de alimento.

Somando-se a todo esse contexto emocional complexo, está a condição de pobreza, com suas consequências nefastas, produzindo inseguranças e estresse. Pais e mães em situação de vulnerabilidade social podem alterar seu comportamento em relação à criança, punindo, bloqueando a afetividade, não respondendo adequadamente às demandas psicossociais do filho, chegando a ser negligentes ou abusivos. ${ }^{15}$

As mudanças provocadas pela vinda do bebê são complexas e não se limitam a variáveis psicológicas e bioquímicas, mas também aos fatores socioeconômicos. Privações reais, sejam afetivas ou econômicas, aumentam a tensão e a preocupação com o futuro, ensejando frustração, raiva e ressentimentos que impedem a mulher de encontrar satisfação na maternidade. ${ }^{19}$

No caso do presente estudo, a mãe assume praticamente sozinha a responsabilidade com os filhos, o que lhe confere posição ainda mais fragilizante. A maternidade se configura em suas vidas de modo conflituoso: por um lado, devem corresponder ao ideal social de amor materno, dedicando-se aos filhos de "corpo e alma"; por outro, internamente, devem lidar com sua desalentadora condição de cuidadoras solitárias e carentes de cuidado e proteção para si mesmas. 
Estudo realizado em Belém, no Pará21 evidenciou que as mães que dividiam a tarefa de cuidar da criança com outras pessoas (companheiro, avó, babá) emitiram com maior frequência comportamentos positivos do que as mães que executavam essas tarefas sozinhas. Os filhos dessas mulheres apresentaram mais comportamentos indicadores de apego, como vocalização, pegar objeto e olhar para mãe. Os autores consideram possível que, ao dividir os cuidados com outra pessoa, a mãe se ache menos estressada, mais tranquila, mais capaz de se comportar sensivelmente perante as demandas infantis quando se encontra na relação com a criança.

\section{(b) Ser mãe: conflitos e contradições}

Aqui surge claramente o paradoxo entre a negação ou o mal-estar em ser mãe e o desempenho dos cuidados maternos de forma satisfatória. As mulheres expressam a dedicação aos filhos, consideram-se boas mães e quem melhor pode cuidar da criança; necessitam da aprovação daqueles com que convivem, inclusive dos próprios filhos; sentirem-se importantes para os filhos parece recompensá-las; as mulheres são apegadas aos filhos e eles a elas. As mães de nossa investigação se contradizem, vivem permeadas por paradoxos e ambiguidades. Não queriam ser mães, mas, em contrapartida, cuidam bem do filho:

Eu perguntei uma vez a ele se ele queria morar com o pai dele, ele não quis. Quer morar comigo. É muito apegado em mim [o filho desnutrido]. Pra onde eu vou ele quer ir. (AMÁLIA)

[...] eu ajeito elas, todo mundo sabe que eu cuido elas bem direitinho. Só quem cuida delas sou eu, tanto faz na doença delas, nos problema quando tá doente, eu tenho mais cuidado porque elas são como são. [...] eu quero muito bem a elas, ave Maria, eu faço tudo por essas menina, tudo. (CLAUDIA)

A responsividade materna é considerada um elemento central para a compreensão do desenvolvimento infantil e este conceito é articulado com a teoria do apego, ${ }^{22}$ que postula que a sobrevivência das crianças depende da manutenção da proximidade de adultos que desempenhem funções de proteção e fornecimento de alimentação, conforto e segurança. A tendência a estabelecer vínculos com determinados indivíduos é um componente essencial da natureza humana e que já está presente ao nascer. ${ }^{18}$

Teóricos do desenvolvimento infantil ${ }^{18,19-23}$ defendem, entretanto, o argumento de que a garantia dos cuidados maternos em si não é suficiente para a constituição psíquica do sujeito. Esses cuidados maternos básicos sem o solo fundante, que é a apropriação da mulher em se constituir como mãe, resultam em falhas e distúrbios no processo de desenvolvimento, separação e autonomia. 
A qualidade das relações de apego (ex.: seguro ou inseguro) depende das interações da díade mãe-criança. O apego seguro, por exemplo, depende da responsividade continente dos pais em relação ao bebê, ou seja, da capacidade do adulto em mostrar-se sensível às pistas da criança e responder nos momentos adequados com o sorriso, a fala, o toque. Nos relacionamentos com as crianças, os cuidadores podem expressar diferentes tipos de responsividade, estabelecendo a confiança ou não na figura de apego, o sentimento de rejeição ou afeição, o sentimento de que o outro é ou não uma base segura para exploração do mundo, definindo a qualidade do apego. ${ }^{22}$

Acrescentamos, ainda, que nesta pesquisa algumas das relações mãe e filho foram percebidas como superprotetoras ou de excesso psicoafetivo por parte da cuidadora. A criança vive, então, muito ligada à figura materna, tendo-a como único referencial de afeto e segurança. As mães parecem superproteger para compensar, inconscientemente, o que elas não têm em sua essência - a vivência positiva e gratificadora em ser mãe. Talvez seja este o verdadeiro alimento que falta a essas crianças, não negando as questões socioeconômicas de privação e desigualdades.

Uma conduta negligente ou mesmo superprotetora por parte dos pais pode acarretar falha no desenvolvimento, comprometendo a alimentação e resultando em baixo peso e baixa estatura para a idade. ${ }^{24}$

\section{(c) Sentimentos ante a desnutrição do filho}

Sentimentos de culpa e vergonha pela magreza do filho permeiam o discurso das mulheres. Elas demonstram certa confusão sobre os motivos que levaram o filho a ser e se manter desnutrido, principalmente quando os outros filhos não o são. Vejamos o que elas expressam:

É assim, com vergonha de sair com ele... pro meio da rua... os pessoal fica tudo olhando. É porque eu acho que pode ser que as outra fala assim: 'ó aí ó, não tem cuidado'. [...] É porque o outro [irmão]... O pessoal fala que: 'esse dai é mais gordo do que o outro'... Porque... que... não sei se é d'eu. Sinto, culpada. (AMÁLIA)

[...] eu me sinto culpada pelos meus filho, porque eu acho assim que eu não estou... mas sempre eu faço a comida certa, na hora certa. (MARÍLIA)

Marília revela, em sua fala, a culpa e se defende, dizendo que faz o que é certo, mas parece haver dificuldades com os limites na educação alimentar e limites da existência do alimento em casa.

[...] é difícil, às vezes um quer comer aquilo, o outro não quer comer, 'ah, mãe eu quero salsicha', as vez eu tenho 50 centavos, 'pois váali, compre 50 centavos de salsicha', ou então 'compre ovo, que é muito mais melhor!' porque o ovo é como lá no IPREDE diz, o ovo tem mais sustança, mais coisa pra dar sustança a ele no cérebro, né, mas ele diz 'ah, mãe, eu quero é salsicha' 'ai! vai, vai, vai menino, compra o que tu quiser lá', pronto!. 
Verificamos achados semelhantes em outro estudo sobre a grande preocupação das mulheres no que diz respeito à alimentação dos filhos, ${ }^{25}$ no qual foram encontradas evidências, nos discursos das mães, de que a desnutrição e a fome estavam entre suas principais inquietações. As autoras também destacam que as mães se sentem confusas e humilhadas diante de suas famílias e vizinhos em decorrência da magreza dos filhos, preocupadas com o possível julgamento de que não seriam capazes de alimentar bem sua família.

Várias características inventariadas por Solymos ${ }^{16}$ estão presentes nas histórias de vida de nossas informantes, o que nos faz refletir sobre a possibilidade dessa identificação da criança com os comportamentos e as situações de sofrimento experienciadas pelas mães desde a gravidez. Chama-nos a atenção o fato de essas crianças estarem sendo acompanhadas por uma instituição competente na área da Nutrição, há mais de dois anos, e permanecerem desnutridas.

Somando-se a essas observações, ouvimos de seis das sete mulheres deste estudo relatos de recusa alimentar por parte das crianças, principalmente com relação à "comida de panela”, refeição considerada de grande importância em seus lares:

Besteira assim [bananada, laranja e bolo] ele come, mas comida de panela, tem dificuldade pra comer. (AMÁLIA)

Surge então uma necessidade de forçar o filho a ingerir o alimento considerado saudável para ganhar algum peso. Aparecem a preocupação constante e o medo de perder o filho em razão de sentimentos de impotência ou culpa. Tentativas frustradas de fazer a criança comer também cansam e confundem as mães.

Eu achava que ela num ia nem se criar! Eu tinha era pena, ela era desse tamainho [mostra com as mãos], uma boneca era maior do que ela! Ainda hoje ela é ruim pra comer [...] tem que tá obrigando ali, [...] ela adoece com freqüência, tem que ter tudo na hora certa, quando já falta alguma coisa eu fico logo preocupada, pensando como eu vou fazer, né? (JANAÍNA)

Isso é outro motivo que eu converso muito com ele 'tu vai morrer, tu vai morrer porque tu não come', mas ele só come se eu tiver com a chinela ali na hora [...]. (MARÍLIA)

Estudo desenvolvido por Lindsay e colaboradores ${ }^{25}$ corrobora o que foi evidenciado pelas mães entrevistadas quanto às preocupações e atitudes das mães relativamente à alimentação de seus filhos. Segundo as autoras, várias mães explicaram que têm que forçar suas crianças a comer alguns alimentos porque eram 'bons para elas'; e que queriam o melhor para seus filhos em todos os aspectos, inclusive assegurando-se de que se alimentassem bem. 
Um aspecto importante, entretanto, chamou-nos a atenção no contexto da recusa alimentar, em razão do seu aspecto contraditório, evidenciando mais uma vez o paradoxo na história das mulheres e de seus filhos desnutridos: as crianças aceitarem se alimentar nas "casas dos outros", ingerindo inclusive o que não aceitam comer em casa:

É isso que eu quero dizer, quando eu vou pra casa da minha família pra gente almoçar, elas comem tudo, come carne, come verdura, come tudo, na casa dos outro! Agora em casa dá trabalho pra comer. Até eu nas casa dos outro eu como tão bem também! As vezes as pessoa, as criança enjoa as comida de casa. Não sei, na casa do meu pai tem a mesma coisa que tem aqui e elas come. (CLÁUDIA)

[...] mas eu acho engraçado é que quando ele tá nas casa ele come, pra mim, ali é uma vergonha! Tem comida em casa, o menino não come, quando está nas casa come! Eu tenho raiva dele por causa disso. Até no meio da rua, o que as pessoa der ele come e em casa ele não come. (MARÍLIA)

Ante a dificuldade de conseguir alimentar adequadamente o filho, livrando-o da desnutrição, confusas, mergulhadas em seus conflitos existenciais, essas mães se defendem, explicando que o problema é com os filhos, que sua magreza é hereditária, ou decorre de problemas de saúde, que é 'seu calibre mesmo' (aludem ao biotipo das crianças); algumas mencionam carência alimentar, outras se justificam pelo receio de não serem consideradas boas mães, procurando medicar os filhos. Novamente, parece-nos que a desnutrição da criança denuncia toda uma realidade de vida difícil de "engolir":

Sim eu tenho [cuidado], né, mas o negócio dele [a desnutrição] é dele mesmo, não é de mim. [...] o peso dele tava muito baixo... ai perguntou [na instituição] por que ele tava mais magro, né, aí eu disse: não porque ele é ruim pra comer, já comprei tanto de vitamina pra ele, mas ele continua do mesmo jeito, cada vez vai ficando mais magro. (AMÁLIA)

[...] eu alimento elas bem direitinho, aí quando elas tão pegando peso, elas recai, é gripe, é febre, é tudo. Que é que eu posso fazer? [...] eu já dei vitamina, dou remédio pra verme, dou tudo, elas não gostam de comer. [...] eu acho que é o peso normal delas mesmo, o calibre delas mesmo, é da família. (CLAUDIA)

Reforçamos que a psicopatologia alimentar reflete uma dinâmica interativa complexa e conflitiva da relação mãe e filho, representada por aspectos tais como: insuficiência ou excesso de investimento libidinal, falta de estímulos, descontinuidade da relação, incoerência na leitura e na resposta às solicitações, interação cronicamente vazia ou bruscamente esvaziada, enfim, irregularidades no vínculo entre o cuidador e sua criança. ${ }^{6}$ 


\section{Considerações finais}

Neste estudo, a desnutrição configurou-se aproximada a dificuldades no estabelecimento da maternidade e do vínculo mãe e filho. Os discursos das mulheres nos revelaram fatores que corroboram tal pensamento: elas afirmaram suas dificuldades em exercer a maternidade por se sentirem despreparadas e desprotegidas, sem companheiro ou familiares presentes e participativos; todas as mulheres foram maltratadas, vítimas de violência e abandono no período da infância e/ou durante a gravidez de seus filhos; mencionaram frequentemente a recusa alimentar dos filhos, os quais, embora não aceitassem o alimento preparado por sua mãe, aceitavam aqueles industrializados e os oferecidos por outras pessoas de sua convivência, evidenciando uma ruptura no vínculo com a mãe. Além desses achados, o fato de terem irmãos não acometidos por desnutrição levou-nos a refletir sobre a possibilidade de uma "identidade desse filho" desnutrido com as condições socioemocionais da mãe e o momento em que ele foi gestado.

Contradições e ambivalências demarcam seus discursos, evidenciando a confusão de seu psiquismo em um contexto conturbado pela insegurança alimentar, pelo meio violento em que estão imersas e pelas redes de apoio instáveis. Em seu estado de miséria e com tantos filhos, a ajuda social de instituições como o IPREDE e do Governo (benefícios e Bolsa Família) não é suficiente para sanar suas necessidades, pois tais suportes apenas amenizam seu sofrimento. Suas condições de moradia e de acesso a bens e serviços são bastante precárias, pois falta saneamento básico, água filtrada, espaços salubres para residir e conviver.

Supõe-se que programas de intervenção nutricional poderão obter resultados mais satisfatórios quando valorizada a história de vida das mães como fator coadjuvante no processo de determinação e recuperação da desnutrição. O fato de compreender como essa mulher convive com o filho em seu habitat natural poderá fornecer subsídios sobre como cuidar melhor, caso a caso. Entende-se que uma atenção psicoemocional mais individualizada e aprofundada à díade poderá favorecer o fortalecimento do vínculo mãe e filho.

Finalizamos, reiterando nosso desejo de que as reflexões aqui desenvolvidas possam contribuir para novas investigações no âmbito da interferência do vínculo mãe e filho nos estados nutricionais infantis, abrindo caminho e incentivo a mais estudos que envolvam a temática da desnutrição.

\section{Agradecimentos}

Ao diretor do IPREDE, Prof. Sulivan Mota, por permitir a realização deste estudo. 


\section{Referências}

1. Lima ALL, Silva ACF, Konno SC, Conde WL, Benício MHD’A, Monteiro CA. Causas do declínio acelerado da desnutrição infantil no Nordeste do Brasil (1986-1996-2006). Rev Saúde Pública 2010; 44(1):17-27.

2. World Health Organization. Department of Nutrition for Health and Development. Global database on child growth and malnutrition. Age range, indicators of malnutrition, measles vaccination coverage and mortality. Disponível em: http://www.who.int/nutgrowthdb/en/

3. Santos RB, Martins PA, Sawaya AL. Estado nutricional, condições socioeconômicas, ambientais e de saúde de crianças moradoras em cortiços e favela. Rev Nutr. 2008; 21(6):671-81.

4. Abreu VJS. Terapêutica nutricional em desnutridos graves hospitalizados. In: Cardoso AL, Lopes LA, Taddei JAAC, coordenadores. Tópicos atuais em nutrição pediátrica. Rio de Janeiro: Atheneu; 2004. p. 63-86.

5. Calvasina PG, Nations MK, Jorge MSB, Sampaio HAC. Fraqueza de nascença: sentidos e significados culturais de impressões maternas na saúde infantil no nordeste brasileiro. Cad Saúde Pública 2007; 23(2):371-80.

6. Sampaio MA, Falbo AR, Camarotti MC, Vasconcelos MGL. Resultados preliminares de um estudo qualitativo sobre a interação entre mãe e criança desnutrida grave, no contexto da hospitalização. Rev Bras Saúde Mater Infant. 2007; 7(Supl.1):S29-S35.

7. Nudelmann C, Halpern R. O papel dos eventos de vida em mães de crianças desnutridas: o outro lado da desnutrição. Ciênc Saúde Coletiva 2011; 16(3):1993-99.

8. Martins IS, Marinho SP, Oliveira DC, Araújo EAC. Pobreza, desnutrição e obesidade: inter-relação de estados nutricionais de indivíduos de uma mesma família. Ciênc Saúde Coletiva 2007; 12(6):1553-65.

9. Martorell R. Consequências de longo prazo da subnutrição no desenvolvimento físico e mental. Anais Nestlé 2001; 61:19-30.

10. Universidade Federal do Ceará. Departamento de Saúde Comunitária; Secretaria de Saúde do Estado do Ceará. Escola de Saúde Pública do Ceará. Fundação Instituto Cearense de Saúde Reprodutiva. Saúde Materno-Infantil no Ceará: 20 anos de acompanhamento. Resultados preliminares da V Pesquisa sobre Saúde Materno-Infantil no Ceará-PESMIC. Fortaleza: UFC; 2008.

11. Minayo MCS. O desafio do conhecimento: pesquisa qualitativa em saúde. São Paulo: Hucitec; 2010.

12. Bosi MLM, Prado SD, Lindsay AC, Machado MMT, Carvalho MCVS. O enfoque qualitativo na avaliação do consumo alimentar: fundamentos, aplicações e considerações operacionais. Physis: Rev Saúde Coletiva 2011; 21(4):1287-96.

13. Deslandes SF, Gomes RA. Pesquisa qualitativa nos serviços de saúde: notas teóricas. In: Bosi MLM, Mercado FJ. Pesquisa qualitativa de serviços de saúde. Petrópolis: Vozes; 2004.

14. Instituto de Promoção da Nutrição e do Desenvolvimento Humano. Dados institucionais. Fortaleza: IPREDE; 2010. 
15. Eickmann SH. Desenvolvimento infantil: fatores determinantes e impacto de um programa psicossocial [tese]. Recife: Universidade Federal de Pernambuco; 2003.

16. Solymos GMB. Vencendo a desnutrição: abordagem psicológica. São Paulo: Salus Paulista; 2002.

17. Vieira VL, Souza JMP, Cervato-Mancuso AM. Insegurança alimentar, vínculo mãe-filho e desnutrição infantil em área de alta vulnerabilidade social. Rev Bras Saúde Mater Infant. 2010; 10(2):199-207.

18. Bowlby J. Apego e perda. $3^{\text {a }}$ ed. São Paulo: Martins Fontes; 2002.

19. Maldonado MTP. Psicologia da gravidez. $17^{\mathrm{a}}$ ed. Petrópolis: Saraiva; 2005.

20. Carvalho AS. Desnutrição infantil e os impasses nas trocas alimentares: uma discussão psicanalítica [dissertação]. Fortaleza: Universidade de Fortaleza; 2011.

21. Silva SSC, Le Pendu Y, Pontes FAR, Dubois M. Sensibilidade materna durante o banho. Psicol Teor Pesqui. 2002; 18(3):345-52.

22. Ribas AFP, Moura MLS. Responsividade materna e teoria do apego: uma discussão crítica do papel de estudos transculturais. Psicol Reflex Crít. 2004; 17(3):315-22.

23. Winnicott DW. Os bebês e suas mães. $3^{a}$ ed. São Paulo: Martins Fontes; 2006.

24. Krugman SD, Dubowitz H. Failure to thrive. Am Fam Physician 2003; 68(5):879-84.

25. Lindsay AC, Machado MMT, Sussner KM, Hardwick CK, Kerr LRFS, Peterson KE. Brazilian mothers' beliefs, attitudes and practices related to child weight status and early feeding within the context of nutrition transition. J Biosoc Sci. 2009; 41(1):21-37. 
